\title{
Multi-grounded action research
}

\section{Göran Goldkuhl ${ }^{1,2}\left(\mathbb{D} \cdot\right.$ Stefan Cronholm ${ }^{3} \mathbb{D} \cdot$ Mikael Lind $^{4,5}$ (D)}

Received: 14 February 2019 / Accepted: 1 April 2020 / Published online: 6 May 2020

(c) The Author(s) 2020

\begin{abstract}
The research approach of multi-grounded action research (MGAR) is presented and analyzed. This is based on a review of issues and concerns in information systems action research. MGAR builds on the epistemological principles of multigrounding. This combines empirical, theoretical and internal grounding. The multigrounded approach builds on elements from grounded theory; i.e. building theory inductively from data through coding procedures, but it also comprises an abductive use of extant theory. MGAR is described through six knowledge contributions: (1) the MGAR process model, (2) the MGAR knowledge model, (3) the MGAR theory model, (4) the principle of the multi-grounded change outcome, (5) the principle of the multi-grounded theory outcome and (6) the principle of mutuality of purposes. MGAR has been applied in an IT service management (ITSM) case, which serves an illustration and a validation of MGAR. In this MGAR case, the improvement of ITSM has been conducted and studied through a multi-organizational setting. In the case, there was a special focus on the service quality of IT services and the relations between service providers and customers.
\end{abstract}

Keywords Action research · Information systems - Qualitative research · Multigrounding · Grounded theory · Empirical grounding · Theoretical grounding · Internal grounding $\cdot$ Situational inquiry $\cdot$ IT service management

Göran Goldkuhl

goran.goldkuhl@liu.se

Stefan Cronholm

stefan.cronholm@hb.se

Mikael Lind

Mikael.Lind@ri.se

1 Department of Management and Engineering, Linköping University, Linköping, Sweden

2 Department of Informatics and Media, Uppsala University, Uppsala, Sweden

3 Department of Business and IT, University of Borås, Borås, Sweden

4 Mobility and Systems, Research Institutes of Sweden (RISE), Gothenburg, Sweden

5 Mechanics and Maritime Sciences (M2), Chalmers University of Technology, Gothenburg, Sweden 


\section{Introduction}

\subsection{Background}

After years of struggle, action research (AR) has emerged as a widely accepted research approach within information systems (IS). The two special issues in Information Technology and People (Kock and Lau 2001) and MIS Quarterly (Baskerville and Myers 2004), together with the compilation of articles in Kock (2007), are signs of this growing recognition. Confer also reviews of action research in IS made by Lau (1997), Baskerville and Wood-Harper (1998), Chiasson et al. (2008), Mathiassen et al. (2012) and Avison et al. (2018). There have been debates and criticisms concerning the scientific legitimacy of AR. It is, however, too early to say that the time of objections and controversies is over; cf. e.g. Avison et al. (2018) about problems to get AR papers published in IS journals. This paper addresses different challenges, controversies and unresolved issues and concerns in action research. These are all issues related to knowledge development in AR. These AR issues are later in this paper summarized in Table 1 and giving codes from \#1 to \#6. These codes are used below in the text in order to ensure traceability.

The key idea of AR is to contribute to both (1) practical problem-solving and change and (2) scientific knowledge production (Rapoport 1970; Susman and Evered 1978; Hult and Lennung 1980). To have a balanced attention to both these purposes is however challenging. The imperative, in AR, to be oriented towards practical change may imply that research aspects sometimes are down-played. Hult and Lennung (1980, p. 242) write that "this emphasis on practice bears a danger that the scientific interest may be reduced to a mere means towards improved problemsolving". The same type of danger is noted by Baskerville (1999, p. 26): "Researchers may become too embroiled in the problem setting, and lose contact with their obligations to develop general knowledge about related theories". Confer also the classical AR dilemma analysis by Rapoport (1970), where criticism is raised that many AR endeavors - being "purely service oriented" towards the client organization-have a very limited theoretical outcome (AR issues \#1 and \#3). At the same time, this might imply a limited theoretical use in the AR process.

The question of the role of theory in AR is not clear-cut in application (AR issues \#2-3). This is clearly demonstrated in the responses from IS scholars about AR difficulties in an inquiry made by Avison et al. (2018). Different views and opinions on this matter can be identified when studying the IS AR literature. Some scholars emphasize the need to let theory inform action and change. Davison et al. (2004) formulate the "principle of theory" that includes arguments for an active use of theory in the AR process. In their articulation of Canonical Action Research (CAR), they explicitly state that "action researchers need to rely on one or more theories to guide and focus their activities" (ibid p. 74). This is also a key argument in Checkland (1991, p. 397) who claims that "there must be an intellectual framework, declared in advance, in terms of which learning will be defined. Without such a framework action research can quickly be indistinguishable from mere action" (AR issue \#2). An emphasis on the use of theoretical 
knowledge means an AR strategy of "knowledge application" as distinguished by Chiasson et al. (2008) and seen as "inference by deduction" (Mathiassen et al. 2012). The opposite (which will be described below) is an AR strategy of "knowledge discovery" (Chiasson et al. 2008) and "inference by induction" (Mathiassen et al. 2012).

There exist scholars who suggest that the theory development process should be fairly inductive and mainly following the principles of grounded theory (GT). Dick (2007) claims that the lack of advice for how to build theory in AR can be fulfilled by the use of a GT approach. Baskerville and Pries-Heje (1999) have elaborated an AR approach ("Grounded Action Research") with integrated elements from GT (Strauss and Corbin 1990). Huxham (2003) argues in the same direction emphasizing that rich data from researcher's close site involvement "have the potential to provide both new and unexpected insights, so theory development processes are inductive-leading to emergent theory" (AR issue \#3). Such an inductive approach is however nuanced by the same author who acknowledges a kind of abductive interplay between data-driven theory-construction and a theory-informing procedure: "Action research will generate emergent theory, in which the theory develops from a synthesis of that which emerges from the data and that which emerges from the use in practice of the body of theory which informed the intervention and research intent." (Eden and Huxham 1996, p. 80).

Classical grounded theory is seen as inductively oriented, which means that theory is built from empirical data (Glaser and Strauss 1967). Even if the strength of this data-driven approach is acknowledged, there are criticisms that the role of extant theory is down-played in grounded theory development (e.g. Thornberg 2012). As an alternative, a multi-grounded approach has been developed, which combines empirical, theoretical and internal grounding (Goldkuhl 2004; Goldkuhl and Cronholm 2010, 2018; Goldkuhl and Lind 2010). We will in this paper exploit the principles of multi-grounding for elaborating action research.

It is not only the role of theorizing that is unclear within AR as described above. The focus of organizational change (as the core of AR) has sometimes also made the functions and ways of data collection unclear. Eden and Huxham (1996, p. 76) are drastic in their critique of some AR studies: "The 'action research' label is often used as a way of excusing sloppy research." Sometimes there is a lack of empirical rigor in AR, which is a serious issue that needs to be addressed (Davison et al. 2004); (AR issue \#4).

It seems that the interest in AR, within IS, is no longer growing, it is rather declining as observed by Avison et al. (2018) through an investigation of a number of AR papers in leading IS journals. However, this decline does not mean that the interest in change and how to direct change has decreased. We would say, on the contrary. However, this interest in how to direct change seems to have been channeled in new ways. There is a huge increased interest in design science within IS. The interest by IS scholars for improvement and change seems, nowadays mainly, to be applied through design science. We would not say that this is negative; on the contrary, we welcome an enhanced design orientation in IS. However, there might be risks and missing opportunities associated with this gradual shift from AR to design science. Organizational change may become restricted to artifact design. There are criticisms 
against some forms of IS design science to be too techno-centric and laboratory-oriented without sufficient anchorage to real practices (Sein et al. 2011; McKay et al. 2012; Iivari 2015). IT induced change should be complemented by other kinds of changes as well (e.g. Wulf and Rohde 1995; Kling and Lamb 1999; Avgerou 2001). In order to utilize AR as a potent and attractive research approach in IS, there is a need to present ways to have designing as a well integrated aspect within AR. There exist several such attempts (e.g. Baskerville et al. 2009; Sein et al. 2011; Wieringa and Morali 2012; Rohde et al. 2016), which will be discussed below in Sect. 2.

\subsection{Purposes, research approach, and structure of the paper}

We have touched upon several important AR issues above; such as the role of theory, how to develop theory, how theorizing interact with problem-solving, how data collection can be exercised with rigor and how design can be well integrated into AR processes. These and related issues will be further discussed in Sect. 2 below and addressed throughout this paper. All these issues are aspects of knowledge development within AR. A general wish is to address these issues in a concerted way and that is the rationale behind this paper. We have formulated a main research question for this work as: How can knowledge development in action research be clarified and improved through the use of multi-grounding principles?

The main purpose of this paper is thus to develop and articulate a multi-grounded action research (MGAR) approach for IS research. Based on the background descriptions above (with unsettled issues, problems, and opportunities) this paper will contribute to the understanding of how to apply the epistemological principles of multi-grounding in information systems action research. An important means for this purpose is the application of MGAR for improvement of IT service management (ITSM) in an action research case.

Our claim in this paper is not that we have found an optimal approach to AR in IS. We do not believe that any such approach exists due to variations in problem settings and research orientations (Avison et al. 2001). There exist many variants of AR both in concept and in application (Baskerville and Wood-Harper 1998; Chiasson et al. 2008; Mathiassen et al. 2012). Our claims are that the presentation of MGAR can (1) contribute to the understanding of important epistemological concerns of $\mathrm{AR}$ and (2) be considered as one useful AR approach. We explicate and relate our developments to other AR approaches in IS, which makes it possible to combine our contributions with those of others.

The accomplishment of this research purpose is done through a conceptual inquiry (Dewey 1938) driven by AR challenges and the idea of multi-grounding. Problematic issues of AR, initially described above, will guide the inquiry process. These and other related issues will be further investigated in Sect. 2 below and summarized in Table 1. The MGAR approach has been applied in the ITSM case and this will serve as an empirical illustration and give a contribution to the validation of MGAR.

The structure of this paper is as follows: In the next section, previous work of $\mathrm{AR}$ is further investigated in order to explicate important issues and concerns. This 
investigation started already in the background descriptions above (Sect. 1.1). In Sect. 3, the multi-grounding principles will be clarified and analyzed. The MGAR approach will be described in Sect. 4, including the six main knowledge contributions of this paper; three MGAR models and three MGAR principles. An action research case "Effective IT service management" will be presented and analyzed in Sect. 5. In Sect. 5.3, an assessment of the MGAR application in the ITSM case will be done as an explicit empirical grounding of MGAR. The paper is ended with discussion and conclusions in Sect. 6. We summarize there how the unsettled issues and concerns have been addressed through our knowledge contributions.

\section{Action research in information systems}

In Sect. 1.1 above, we reviewed some problems and issues in AR as a background for this paper. We will continue this review here, with special emphasis on AR in IS research. We have seen pioneer contributions within IS like ETHICS (Mumford 2006), Soft Systems Methodology_SSM-(Checkland 2000) and Multiview (Avison and Wood-Harper 1991). ETHICS was based on a socio-technical view with a balanced development of both "social system" and "technical system". User participation was emphasized. SSM builds on systemic thinking taking a holistic approach to organizations and their development. The systemic change process according to SSM was seen as an inquiring and learning process governed by special elaborations of core conceptions of the studied human activity system. With inspiration from socio-technical and soft systems thinking, Avison and Wood-Harper (1991) integrated elements from different systems development approaches into a contingency oriented AR approach called Multiview. These pioneering contributions can all be said to be approaches for a research-influenced change of organizations in a balanced way. The main idea seems to be the use of certain research perspectives to improve IS development to be organizationally sound. The process models comprised in these approaches are dominated by an organizational change perspective. Explicit research activities are down-played.

This first emphasis of IS AR on organizational change was followed by attempts to clarify the research character of AR. Baskerville and Wood-Harper (1998) positioned IS AR in the historical evolution of different AR traditions. Later Baskerville and Myers (2004) positioned AR clearly within the tradition of philosophical pragmatism. Davison et al. (2004) made an important work to clarify several AR principles within Canonical Action Research following the AR process model of Susman and Evered (1978) with the five generic phases (diagnosing, action planning, action taking, evaluating, specifying learning). However, these process models still have a bias towards organizational change.

McKay and Marshall (2001) have presented an alternative conceptualization of AR. They have differentiated a research interest cycle from a practical problem-solving cycle. This means that their model includes explicit research-oriented stages. However, the two cycles resemble each other using the same set of generic problemsolving activities, which leaves room for further elaboration of the research character of AR (Goldkuhl 2012). The two cycles are said to interact with each other but 
more knowledge about how such interaction is needed to make this approach more actionable (AR issue \#1). Chiasson et al. (2008) and Mathiassen et al. (2012) build on this important differentiation into research interests vs. problem-solving interests and these authors have furthered it through the concepts of knowledge discovery vs. knowledge application and consequentially different inference styles (induction vs. deduction); these concepts are mentioned above in Sect. 1.1.

There are many scholars who see AR as an integral work package with no such clear differentiation into research and problem-solving purposes. There exist strategic discussions about how to control such an integral project (Avison et al. 2001; Heron and Reason 2001; Schein 2001; Chiasson et al. 2008). Different positions are conveyed in this literature; researcher-led vs. practitioner-led vs. jointly led. The focus in these discussions seems to be on the formulation and accomplishment of problem-solving purposes. Schein (2001) emphasizes that researchers should embrace the practitioners' problems and let them guide their research interest. Heron and Reason (2001) take an "extreme" collaborative position when they emphasize that all decisions about content and methods in an AR project should be taken by the researchers and the practitioners jointly (AR issue \#4).

Another important contribution of explicating the research character is made by Baskerville (1997) where he has tried to draw a sharp line between AR and organizational consulting although they may share a common intellectual heritage from Lewin (1947) and Trist (1981). In a similar vein, Mårtensson and Lee (2004) have in their Dialogical AR approach distinguished between researcher roles and practitioner roles in change collaborations. They have made a clear separation in that the researcher role is focused on theoretical reflection and practical advice and the practitioner's role in problem description and action taking. However, this approach seems to miss important potentials of the researcher being actively engaged in empirical data collection and intervention. The researcher needs in this approach to totally rely on the practitioner's ability to carry out data collection and intervention.

The issue of theory use in AR has been addressed by Davison et al. (2004, 2012). A concern is the lack of active use of theory in AR studies. Davison et al. (2012) conducted a literature review of AR papers in leading IS journals with a focus on their engagement with theory. They conclude that only a small portion report on the use of, what they call, "instrumental theory" in the AR process (AR issue \#2). It is here also interesting to read why Argyris et al. (1985) have chosen to avoid using the label "action research" although their ("action science") approach resembles AR to a great extent: "We would be content to use the term action research if it were not for two reasons. First, over the years action research has often been separated from theory building and testing" (ibid p x).

Davison et al. (2004) have identified the disagreements among scholars about theory use in AR: (1) That some scholars claim, in the spirit of qualitative and openminded research, to be cautious with using any theory in early problem-finding stages, (2) while others demand the importance of defining theory/framework in advance (as e.g. Checkland 2000).

In Davison et al. (2012), these scholars are adjusting and refining their earlier work on CAR in IS (Davison et al. 2004) concerning theory use in AR (issue \#2). They are critically assessing their previous work concerning a lack of precision 
in the guidelines for theory use. They have, in their later publication, introduced more advice concerning how to use theory and in what AR stage. They distinguish between two types of theories (focal theory and instrumental theory). There is, however, hard to find any clear criteria to differentiate between these two types of theories. Both types of theories are intended to be used to guide the problemsolving in AR. Davison et al. (2012) have a strong emphasis on selecting a theory to inform action planning when outlining a course of action. Their reasoning seems to be hard to harmonize with an inductive theory emergence approach. Their basic stance seems to be "inference by deduction" to use the words from Mathiassen et al. (2012).

Recent development in IS contain attempts to explicitly integrate a design perspective into $A R$ and thus import ideas from the design science (DS) movement. Sein et al. (2011) made, based on previous work by Lindgren et al. (2004), an important contribution when developing the Action Design Research (ADR) approach. The vantage point of these authors is a discontent with a narrow-minded design science in IS: "current DR [Design Research] methods ... consider organizational intervention to be secondary" (ibid p 39). They suggest a fusion of design science and action research resulting in the ADR approach. Sein et al. have definitely made an important contribution when pushing IS design science in an AR direction. However, there exist some unhappy obscurities in their approach. They have merged build, intervene and evaluate activities into an integrated "BIE" chunk, which has made these activities and their relations as conceptually unclear. The interplay between situational design and abstracted conceptualization and learning is discussed by the authors, however not clearly reflected in their process models. ADR is not the only approach attempting to fuse AR and DS. Another example is Soft Design Science Methodology by Baskerville et al. (2009). These scholars have used SSM as an intellectual tool to combine AR and DS. Their emphasis in this approach is the interplay between specific problems and solutions vs. general problems and solutions. In Technical Action Research (Wieringa and Morali 2012) there is a similar differentiation between (1) working with a class of problems (through artifact design) and (2) helping a client with specific problems through a new artifact. Wieringa and Morali (2012) emphasize also a third layer (addressing a research problem) which is analytically separated from the other two. Another example is Grounded Design (Rohde et al. 2016). These scholars emphasize the occurrence of an appropriation process after implementing an IT artifact in a social practice, which have important implications for a design-oriented AR process: opportunities for redesign of the artifact may emerge organically in the appropriation process and which were not anticipated before in the initial design. Therefore, designing should be considered as an iterative process with recurrent testing in real settings.

A review of AR literature has been conducted in this section and in Sect. 1.1 above. We summarize issues and concerns of this discussion in Table 1 as a basis for further treatment in the paper. We formulate questions concerning knowledge development in AR and based on the literature review, that do not seem to have reached a final settlement. We will address these issues through the proposed research approach of multi-grounded action research. An explicit response to these issues will be presented in Sect. 6.2 (Table 4). Three issues in Table 1 are concerned 
Table 1 Issues and concerns of knowledge development in action research that need clarification and resolution

\begin{tabular}{|c|c|}
\hline AR issues & Literature references \\
\hline $\begin{array}{l}\text { \#1. How should problem-solving and theorizing } \\
\text { interact during AR? }\end{array}$ & $\begin{array}{l}\text { Rapoport (1970), Hult and Lennung (1980), } \\
\text { Baskerville (1999), McKay and Marshall } \\
\text { (2001), Davison et al. (2004), Chiasson et al. } \\
\text { (2008), Mathiassen et al. (2012), Avison et al. } \\
\text { (2018) }\end{array}$ \\
\hline \#2. How should theory be used in AR? & Checkland (1991), Davison et al. (2004, 2012) \\
\hline \#3. How should theory be generated in AR? & $\begin{array}{l}\text { Argyris et al. (1985), Eden and Huxham (1996), } \\
\text { Baskerville and Pries-Heje (1999), Huxham } \\
\text { (2003), Davison et al. (2004, 2012), Dick } \\
\text { (2007) }\end{array}$ \\
\hline $\begin{array}{l}\text { \#4. How can research purposes and problem-solving } \\
\text { purposes interact in AR? }\end{array}$ & $\begin{array}{l}\text { Avison et al. (2001), Heron and Reason (2001), } \\
\text { McKay and Marshall (2001), Schein (2001), } \\
\text { Chiasson et al. (2008) }\end{array}$ \\
\hline $\begin{array}{l}\text { \#5. What are the roles of data collection and data } \\
\text { analysis for problem-solving and theorizing in AR? }\end{array}$ & $\begin{array}{l}\text { Eden and Huxham (1996), Davison et al. (2004), } \\
\text { Mårtensson and Lee (2004) }\end{array}$ \\
\hline \#6. What is the role of design in AR? & $\begin{array}{l}\text { Baskerville et al. (2009), Sein et al. (2011), Wier- } \\
\text { inga and Morali (2012), McKay et al. (2012), } \\
\text { Rohde et al. (2016) }\end{array}$ \\
\hline
\end{tabular}

with the role of theory; how theorizing interacts with problem-solving (\#1), how to use theory (\#2), and how to generate theory (\#3). The first issue (\#1) relates to issue \#4, which is the interaction between research purpose and problem-solving purpose. This means that \#4 is about purposes and \#1 is about the accomplishment of activities. The last two issues are concerned with two other important aspects of AR; data collection/data analysis (\#5) and design (\#6).

\section{Multi-grounding principles}

As a foundation for the action research approach (MGAR) suggested and used in this paper, the epistemological principles of multi-grounding will be presented and analyzed in this section. Multi-grounding has been described in several publications (e.g. Goldkuhl 2004; Goldkuhl and Cronholm 2010, 2018; Goldkuhl and Lind 2010; Hultgren and Goldkuhl 2013). It is inspired by the grounded theory (GT) approach (Glaser and Strauss 1967; Strauss and Corbin 1990; Corbin and Strauss 2008), but at the same, it is based on criticism of GT (Goldkuhl and Cronholm 2010). The main idea of classical GT is to build theory from data, i.e. an inductive approach to knowledge creation and theory development. This is also how Bryant and Charmaz (2007) characterize GT in the introduction of their SAGE Handbook of Grounded Theory. In this introduction, they make a reference to Wittgenstein's (1958) admonition "don't think, but look!", which should be seen as a strong advice to start from empirics instead of pre-conceptions. Original GT (Glaser and Strauss 1967) had a strong emphasis on starting the analysis from data in an inductive way and leaving 
out theory-based conceptions. There is a very strong, and later debated, statement in their book: "An effective strategy is, at first, literally to ignore the literature of theory and fact on the area under study, in order to assure that the emergence of categories will not be contaminated by concepts more suited to different areas" (Glaser and Strauss 1967, p. 37).

Grounded theory has later been divided into several variants with the two originators as progenitors for each such variant (Strauss and Corbin 1990; Glaser 1992). One strong reason for this split into different variants seems to be the use of pre-conceptions in the analysis process, where Glaser seems to take an "orthodox" position emphasizing a strict inductive analysis. Even if there are other nuances in the writings of Strauss, there is, however, no doubt that his approach comprises the original maxim of building theory inductively from data. We comment further below on such nuances of inductivism.

Multi-grounding acknowledges the importance of an inductive and open-minded approach towards the analysis of data, but it does not see this kind of approach as excluding an active use of theories at certain stages in data analysis and concept formation. As expressed by GT advocates, pre-conceptions of extant theories can blind scholars for nuances and potential discoveries in empirical data. However, theories can function in an opposite and positive way: They can guide scholars' attention to empirical phenomena that otherwise would have been missed (Cronen 2001). To build a theory from data without taking into account pre-existing knowledge (codified in extant theories) entails the risk of "re-inventing the wheel" or creating "an isolated island" (Goldkuhl and Cronholm 2010). Science has often cumulative ambitions and it is crucial to build on previous knowledge or at least to relate and position the developed knowledge to the extant knowing. Thornberg (2012, p. 255) describes, in an eloquent way, a sensible use of pre-existing theories in data analysis and theory formation: "the researcher takes the advantage of pre-existing theories and research findings in the substantive field in a sensitive, creative, and flexible way. These are not uncritically adopted in the analysis but are judged in terms of their relevance, fit, and utility". To use existing theory in qualitative case-study research is a way of avoiding the risk of over-generalization from few cases (Goldkuhl and Cronholm 2010). As a whole, multi-grounding is rather an abductive approach than a strict inductive approach. The meaning of abduction is the integration of previous theoretical knowledge and new experience (Kelle 2005; Van Maanen et al. 2007). It is described by Thornberg (2012, p. 247) in the following way: "a researcher who uses abductive reasoning constantly moves back and forward between data and preexisting knowledge or theories, and makes comparisons and interpretations in the searching for patterns and best possible explanations".

The multi-grounded approach comprises, thus, both empirical and theoretical grounding for the emerging theoretical knowledge. It also includes a third type of grounding called internal grounding. This means the use of the emergent knowledge itself in a grounding process. The aim is to reach a congruent and coherent theoretical outcome. In order to do this, the internal coherence must be continuously checked. Different constructs need to be harmonious to each other. These three grounding principles (of multi-grounding) are depicted in Fig. 1. The emerging theoretical knowledge should thus be grounded in different knowledge sources: 
Fig. 1 Three grounding procedures (based on Goldkuhl 2004; Goldkuhl and Cronholm 2010)

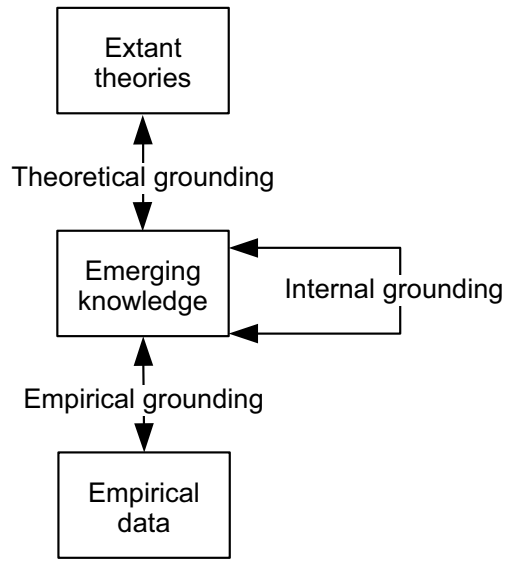

- Empirical data (through empirical grounding)

- Extant theories (through theoretical grounding)

- Itself (through internal grounding)

The concept of grounding comprises both generation and validation of knowledge. In classical GT, empirical data are used as a basis for building theory and as a basis for validating the emergent theory. In MGT, there are, besides empirical data, two other knowledge sources that are used for generation and justifying the emergent theory: extant theory and the emergent theory itself.

GT comprises different coding procedures, i.e. going from data via concepts and categories to theory. In Strauss and Corbin (1990) three coding procedures are described: open coding (i.e. the initial conceptualization of data), axial coding (i.e. building structures of categories) and selective coding (i.e. finding a core category). In Goldkuhl and Cronholm (2010) there is a comparison between grounded theory and multi-grounded theory (MGT) concerning coding. MGT builds on GT coding but has made some slight modifications in procedures and labeling. Open coding is applied in a similar way in MGT with the label of "inductive coding". This is complemented in MGT with conceptual refinement as a specific way of concept definition. Axial coding in GT is done in a similar way in MGT using an "action paradigm", but under the label of "pattern coding". In MGT there is no requirement for finding one core category, but agreeing to a goal of densifying the theory outcome. This type of coding is labeled "theory condensation" in MGT.

What is said about theory use in multi-grounded studies? Hultgren and Goldkuhl (2013) have brought in the notion of practical theory (Craig and Tracy 1995; Cronen 2001) as a constructive perspective on theory use in MGT studies. The notion of practical theory emphasizes the functional aspect of knowledge, as being useful for action. This has its clear roots in pragmatism and especially the works on pragmatic inquiry (Dewey 1938). Cronen (2001, p 30) motivates the use of a practical theory in the following way: "Its use should, to offer a few examples, make one a more sensitive observer of details of action, better at asking useful questions, more capable 
of seeing the ways action are patterned, and more adept at forming systemic hypotheses and entertaining alternatives". This resonates well with theory use in AR; that a theory should inform investigations and the creation of possible change measures.

What is said about the theoretical outcomes of multi-grounded studies? Goldkuhl (2004) has made an epistemological investigation with a focus on multigrounded design theory. Such a theory is defined as a prescriptive theory giving advice for actions. However, this kind of knowledge is dependent on other forms of knowledge, such as conceptual, normative and explanatory knowledge. It is important to acknowledge that the aim of the intended theory will govern its epistemological character (Habermas 1984). If the aim is to govern design, there is a clear need for prescriptions, but also for explanations (Goldkuhl 2004; Kuechler and Vaishnavi 2012). There can be other theory purposes, like analysis and understanding (Gregor 2006), which mainly requires conceptual and explanatory modes of knowledge. A multi-grounded theory can include several epistemological forms (as conceptual, explanatory, normative, prescriptive), but such a theory should not be restricted to any such form. There should be an openness to epistemological characters dependent on theoretical purposes.

Multi-grounding has been applied in design research. Goldkuhl and Lind (2010) make, in such a research, a differentiation between situational and abstract design knowledge. Situational design knowledge is knowledge produced in the concrete design endeavor (e.g. problem descriptions, design models). Abstract design knowledge is theorized knowledge that can be used as a knowledge support for design and as a theoretical outcome from the research process. Goldkuhl and Lind (2010) apply multi-grounding principles to both situational and abstract knowledge. This means that not only abstract/theoretical knowledge should be empirically, theoretically and internally grounded, but this counts also for situational design knowledge.

The multi-grounded research approach has been applied in many studies. Several such studies are mentioned and described in Goldkuhl and Cronholm (2010, 2018) and Goldkuhl and Lind (2010). Karlsson and Ågerfalk (2007) have applied a multi-grounded approach in AR studies on IS development method configuration. They applied multi-grounding principles together with the process model of Canonical Action Research (Susman and Evered 1978). Their work did not comprise any new development of a specific MGAR approach. The experiences from their work demonstrate, however, a good potential for applying multi-grounding principles in AR. Their studies were published in 2007, and they were not influenced by the later development of multi-grounding principles (Goldkuhl and Cronholm 2010; Goldkuhl and Lind 2010).

\section{Process and principles of multi-grounded action research}

The multi-grounded action research approach is described in this section. The description is structured in six inter-related knowledge contributions: 
1. The MGAR process model

2. The MGAR knowledge model

3. The MGAR theory model

4. The principle of the multi-grounded change outcome

5. The principle of the multi-grounded theory outcome

6. The principle of mutuality of purposes

These six knowledge contributions fulfill the primary purpose of this paper, i.e. clarifying how to apply the epistemological principles of multi-grounding in information systems action research.

The development of MGAR can be seen as a result of a multi-grounded research process in itself. The description of MGAR below is the main knowledge contribution of this paper. This research approach has emerged through a series of iterations of empirical and theoretical work. It is cumulative in the sense that it integrates important elements from previous research like knowledge about AR (Sects. 1.1 and 2) and GT and MGT knowledge (Sect. 3). This MGAR description has not previously been presented in this concerted way. Different empirical studies, where multigrounding principles have been applied, have influenced the emergence of MGAR. We have selected the ITSM case as a model case to illustrate MGAR in this paper and thereby also to contribute to its empirical grounding (Sect. 5.3 below). Principles of MGAR have been applied in this case and thereby contributed to its successful performance. Learnings from this application have also contributed to this succinct presentation of MGAR.

\subsection{The MGAR process model}

Multi-grounded action research consists of two mutually supportive sub-processes running in parallel (Fig. 2):

- Theorizing

- Situational inquiry

This division is inspired by similar divisions made for design research (e.g. Goldkuhl and Lind 2010; Lee et al. 2011; Goldkuhl and Sjöström 2018). It is important to analytically distinguish between the practical problem-solving and the theorizing activities; cf. the differentiation between problem-solving interest and research interest in AR made by McKay and Marshall (2001). As stated in Sect. 2 above, there is an organizational change bias in AR process models (like Susman and Evered 1978). The clear analytical differentiation, in MGAR, into theorizing and situational inquiry is a response to this bias and thus to make theorizing to an "equal companion" to the empirical change process of situational inquiry. Theorizing is not something you do only after the empirical inquiry stages as described in Canonical AR (Susman and Evered 1978). It runs in parallel with the empirical change process (Goldkuhl 2012).

We need to explain our terminology for these two sub-processes. As said above, our division resembles the differentiation into a "problem-solving interest 


\section{Theorizing}

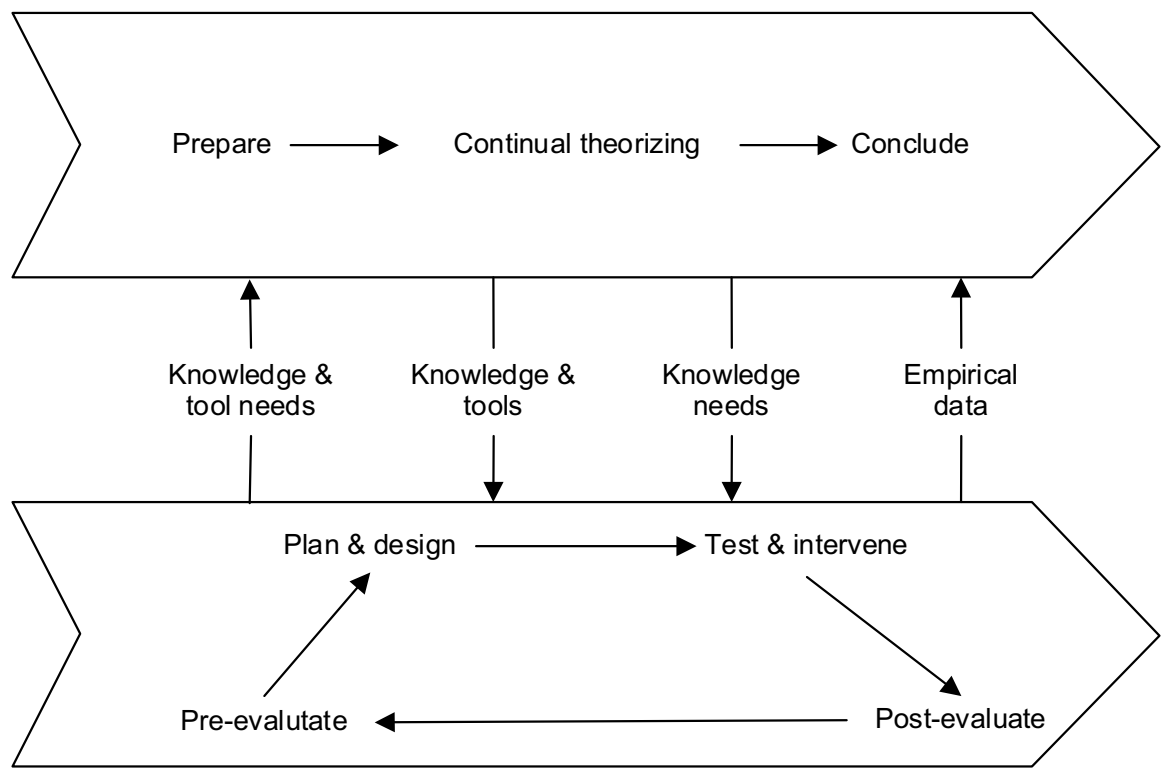

Situational inquiry

Fig. 2 The multi-grounded action research process model (with inspiration from Goldkuhl 2012; Goldkuhl and Sjöström 2018)

cycle" and a "research interest cycle" as made by Mckay and Marshall (2001). Their terminology has been used and abbreviated by Chiasson et al. (2008) and Mathiassen et al. (2012): "research cycle" and "problem-solving cycle". We think that the term "problem-solving" is in principle acceptable. It is widely used and it gives a fair characterization of this kind of activity. We can use it as a synonym to our preferred term "situational inquiry". We have chosen this term since (1) it gives a linkage to roots in pragmatist philosophy (the inquiry notion as explicated by Dewey 1938) and (2) it makes clear a differentiation ("situational") to its AR activity companion of "theorizing".

We find it inadequate to label this companion a "research cycle" or something like that. This makes it sound, as the other part ("problem-solving") is not part of the research process. Problem-solving/situational inquiry should be seen as a change-oriented empirical inquiry and as such, it is a necessary and integral part of the action research process. What is not directly empirical/situational work in AR is work with abstractions, literature reviews and theory development. These kinds of activities are labeled "theorizing" in MGAR. Theorizing and situational inquiry form together the research within AR. Situational inquiry has the dual role of being both part of research and part of an organizational problem-solving activity.

Situational inquiry (SI) consists of four activities that can be performed in an iterative fashion (Goldkuhl and Sjöström 2018): 
- Pre-evaluate

- Plan \& design

- Test \& intervene

- Post-evaluate

This subdivision resembles the structure of Canonical Action Research-CAR (Susman and Evered 1978; Davison et al. 2004). Pre-evaluate (of MGAR) corresponds to diagnosing (of CAR), plan \& design corresponds to action planning, test $\&$ intervene corresponds to action taking and post-evaluate corresponds to evaluation. In CAR there is a fifth activity (specifying learning). This corresponds partly to post-evaluate in MGAR and partly to theorizing. As described above, theorizing is, in MGAR, distinguished as a separate sub-activity, running in parallel to practical problem-solving (situational inquiry) and not just something that appears afterward.

As seen above, we have adopted a partially different terminology than CAR for the sub-processes. We state the following reasons for this: The initial description and assessment of problems is in CAR called diagnosing and the final assessment of conducted changes is called evaluation. We find it hard to see why these two evaluative activities are labeled in such different ways. We call instead the initial (problemoriented) activity of the inquiry "pre-evaluate" and the final activity "post-evaluate". This is done in order to emphasize the evaluative character of both these activities. In CAR there are two middle activities of action planning and action taking. The corresponding activities of MGAR have also been re-labeled. We are influenced by the design science turn in IS. We add "design" to the second stage and call it "plan \& design". This is not only to acknowledge a possible combination of digital and organizational design. There is also a growing design orientation in management and organizational change (Boland and Collopy 2004; Van Aken 2005) that should be recognized. As a consequence of this stressed design orientation in the MGAR labeling, we have added the term "test" in the third activity ("test \& intervene"). We follow here the ideas of Rohde et al. (2016) and Sein et al. (2011) about continuously intervening and testing (appropriating) new measures.

Theorizing in MGAR consists of three consecutive activities (Goldkuhl and Sjöström 2018):

- Prepare

- Continual theorizing

- Conclude

The prepare phase consists of an initial formulation of research interest and research questions, an initial establishment of the knowledge base for the study (i.e. literature search and study) and initial arrangements for the empirical/intervention work in situational inquiry. This includes also furnishing of instrumental theory as "cognitive tools" for SI. Continual theorizing consists of several generic activities such as search and supply (of relevant extant knowledge to be valued and possibly used in the AR research process), formulation of hypotheses (or other conjectures) to study in the empirical SI, analysis of empirical data with abstraction/construction of categories, development/adaptation of theories, models and other conceptual tools, and 


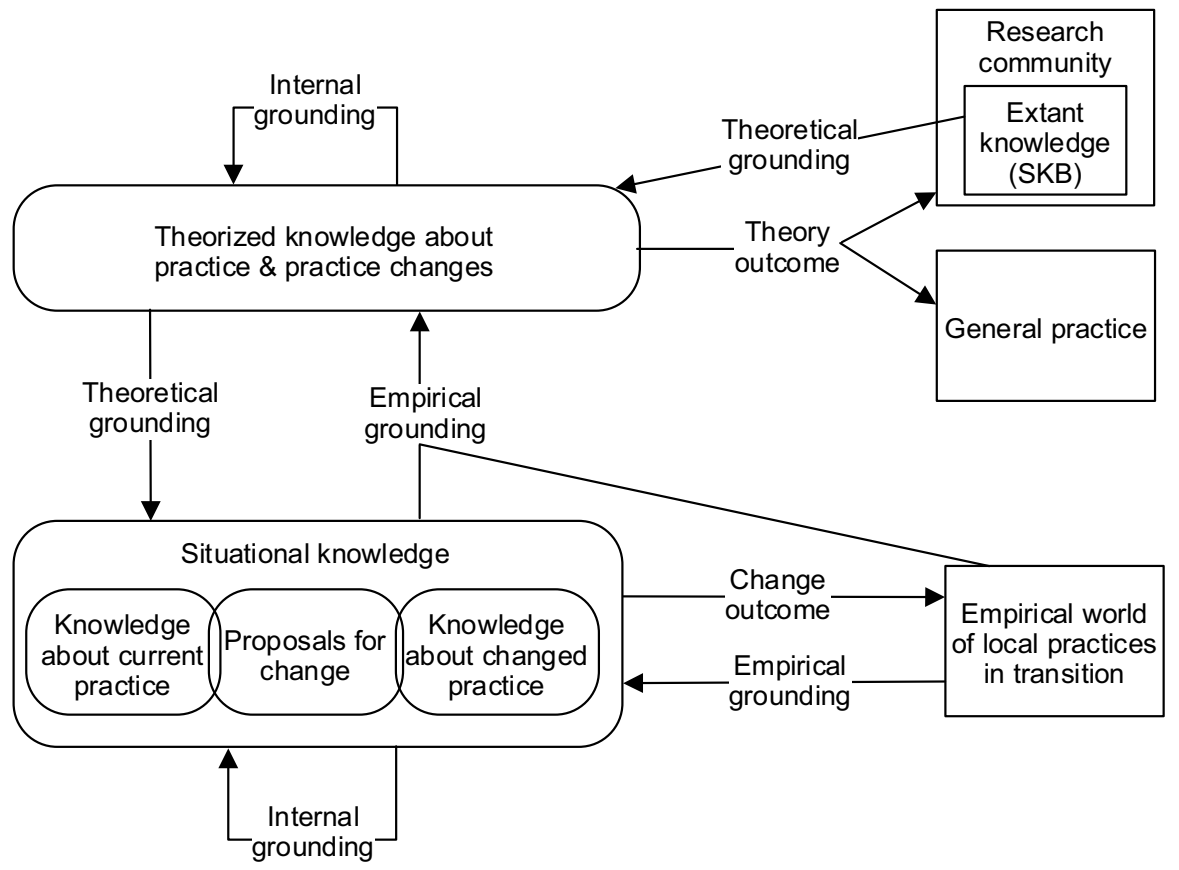

Fig. 3 The multi-grounded action research knowledge model

a continual reflection of research interests/questions and inquiry interests including a possible re-formulation of research interests. Conclude corresponds to the final generation of the abstract/theoretical outcome from action research.

Several of these activities are well-known in the research methodology literature. They are, however, not well described in the AR literature, which can make them invisible, especially to novices, and therefore entail the risk of having them downplayed. In order to avoid the risk of losing oneself into the organizational change process (Rapoport 1970; Hult and Lennung 1980; Baskerville 1999), there is a definitive need to make such theorizing activities explicit and to apply them continuously during the AR process.

There is a continual interaction between situational inquiry and theorizing during the MGAR process. This interaction is governed by different knowledge objects as can be seen from Fig. 2. This interaction is further described in Sect. 4.4 in connection with AR principle 3.

\subsection{The MGAR knowledge model}

The two sub-processes of MGAR (i.e. theorizing and situational inquiry) comprise the development of diverse kinds of knowledge (Fig. 3). Theorizing means the formulation of abstract and theorized knowledge about practices and practice change. This kind of knowledge can be addressed to both scholars in the research 
community and to practitioners in general (Goldkuhl 2012). In situational inquiry, there is a knowledge development that is well integrated within the practice development. This situational knowledge is divided here into three distinct categories:

- Knowledge about current practice (generated through pre-evaluate)

- Proposals for change (generated through plan \& design)

- Knowledge about changed practice (generated through test \& intervene and postevaluate)

One main idea of MGAR is that both these types of knowledge (theorized vs. situational knowledge) should be multi-grounded. These knowledge types should be empirically, theoretically and internally grounded. This will be further elaborated in Sect. 4.4 below.

\subsection{The MGAR theory model}

How to deal with theory is crucial in MGAR. The role of theory is considered as salient when looking back on our review of extant literature in Sects. 1.1 and 2. There are three issues stated in Table 1 that relates especially to theorizing (AR issues \#1-3). The MGAR theory model (Fig. 4) should be seen as expounding the MGAR knowledge model (Fig. 3) with a special focus on theory use and generation.

In MGAR, and described in the MGAR theory model, we distinguish between four types of theory in action research:

- Extant theory

- Emergent theory

- Instrumental theory

- Final theory

Extant theory in the MGAR process is theory that is selected from the scholarly knowledge base (SKB) because it is considered relevant and useful, in one way or the other, for the knowledge development in AR. Such a theory can be identified and selected before a specific AR study due to its relevance for the study domain. A specific extant theory can also be identified and selected later in the process due to discovered empirical circumstances in the situational inquiry. Emergent theory is theory that is continually created during the AR process with influence from empirics. Emergent theory may also be influenced by selected extant theory. Instrumental theory is theory that is used to inform problem-solving/situational inquiry. Instrumental theory can be (1) extant theory selected from SKB or (2) emergent theory generated through theorizing as part of the AR endeavor. We use the term "instrumental theory" based on Davison et al. (2012). Another possible term would be "practical theory" as described in Sect. 3 above. However, a practical theory contains a more general feature of being "practical" for many kinds of human affairs (Cronen 2001). The term "instrumental" is here restricted to supportive uses in the problem-solving process of AR. Instrumental theory includes all possible cognitive 


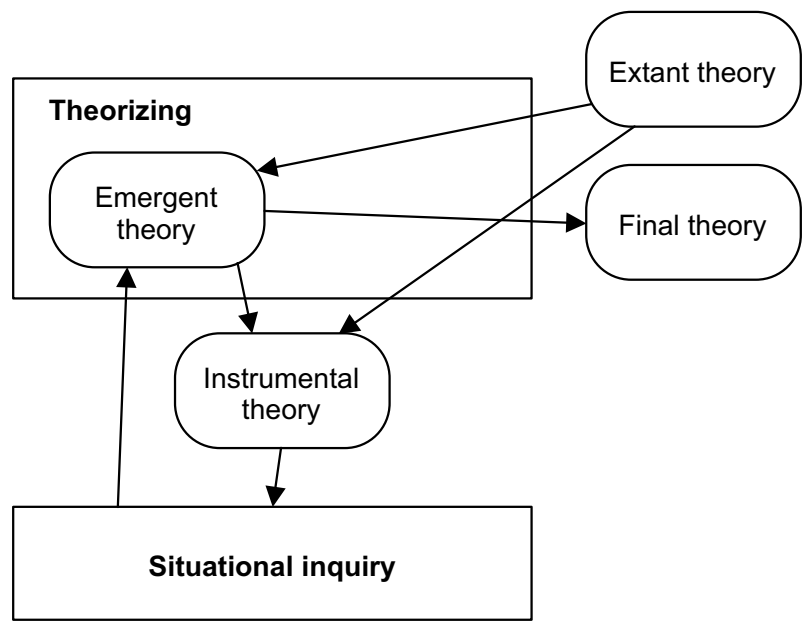

Fig. 4 The multi-grounded action research theory model

tools (as e.g. established theories, conceptual frameworks, models, evaluation criteria, design templates) that are considered useful for situational inquiry and its different stages. Final theory is the outcome of AR/theorizing; i.e. the finalized emergent theory. It is with some hesitance we use the term "final theory". In an epistemology founded in the philosophy of pragmatism (e.g. Dewey 1938), there is no such thing as a final theory, since theoretical knowledge is always provisional and evolving. It is, however, at certain points in time possible to consider something as finalized or at least as "temporarily stable". The theoretical outcome from a specific AR project documented in a scholarly publication can be said, at that time, to be "final theory", although it may be subject to a possible revision in the future.

It should be noted that these four theory types do not differ concerning possible content. The differentiation into these types is made concerning the processes of generation and use. Emergent theory can also be instrumental theory and final theory. Extant theory can be instrumental theory.

In MGAR, theories are used to inform situational inquiry and theorizing. Theories to be used in theorizing are selected from the scholarly knowledge base. Theories to be used in situational inquiry are selected and adapted to such problem-solving in order to be instrumental. What is the role of theory in situational inquiry in relation to strategies of knowledge discovery vs. knowledge application (Mathiassen et al. 2012)? There is a strong empirical impetus in MGAR with inspiration from classical GT (Glaser and Strauss 1967). Let the empirical world and its intrinsic properties come first and not what and how we think of it. This means that we, as MGAR investigators, should be cautious to use instrumental theory too early in the empirical processes. First of all, be open-minded aiming for discovery through data collection and data analysis. After such an open search, it is possible to switch to an active use of instrumental theory in order to detect other aspects, which might be missed without the use of such cumulative knowledge. This means also that the 
generation of emergent theory should follow such a principal sequence: First, generate abstractions in an inductive way based on data that are captured with little theoretical pre-conceptions. Then, integrate data that are influenced by the use of extant theoretical codes. Further development of emergent theory can later be conducted with influence from (1) more data that are generated based on the instrumental application of this emergent theory and (2) extant theories (from SKB) that are selected due to findings expressed in the emergent theory. To this, we need to add the MGAR ambition of developing a conceptually clear and coherent theory through internal grounding.

Instrumental theory can be used in all stages of the situational inquiry. It can be used in pre-evaluate in order to arrive at a clear and theorized view of the current problematic situation. It can be used in plan \& design and test $\&$ intervene to give inspiration to advanced and suitable change measures and their implementations. It can be used in post-evaluate in order to arrive at clear views of the impact of change. In all these stages, we want to express the primacy of situational knowledge. Theories might definitely be useful, but a stiff theory use in AR entails the risk of pushing local knowledge aside, destroying creativity and discouraging practitioners and their engagement and confidence.

\subsection{Three principles of MGAR}

Based on the idea of multi-grounding both theorized and situational knowledge follows two principles of multi-grounded action research:

1. The principle of the multi-grounded change outcome

2. The principle of the multi-grounded theory outcome

The principle of the multi-grounded change outcome means that the proposed and implemented change measures in the focused practice should be empirically, theoretically and internally grounded. This includes also the pre-requisites of these change outcomes; i.e. (1) diagnostic knowledge about current practice generated through pre-evaluate and (2) the proposed changes formulated through plan $\&$ design (Fig. 2). The principle of the multi-grounded theory outcome means that the generated abstract knowledge should be empirically, theoretically and internally grounded. The grounding of each outcome is further described in Table 2.

Besides these two principles, we have formulated a third MGAR principle:

\section{The principle of mutuality of purposes}

Action research aims at both organizational change and scientific contribution (see Sect. 1.1 above). From the local practitioners' perspective, it is most important to arrive at appropriate change outcomes. The conduct of research activities, the researchers' involvement and the provision of research-based knowledge are all instrumental in relation to these practical purposes. When flipping the coin, 
Table 2 Two MGAR principles

\begin{tabular}{lll}
\hline & Change outcome & Theory outcome \\
\hline Empirical grounding & $\begin{array}{c}\text { Based on thorough data collection and } \\
\text { evaluation of (1) problems, goals, and } \\
\text { needs of the current practice and of (2) } \\
\text { experiences from changed practice }\end{array}$ & $\begin{array}{c}\text { Based on empirical data from } \\
\text { inquired practice, change process } \\
\text { and change outcome }\end{array}$ \\
Theoretical grounding & $\begin{array}{c}\text { Informed by instrumental theory, i.e. } \\
\text { extant and/or emergent theory } \\
\text { Internal grounding }\end{array}$ & $\begin{array}{c}\text { In accordance with parts of extant } \\
\text { theory } \\
\text { elements }\end{array}$ \\
\hline
\end{tabular}

the scientific purpose of creating contributions to the scientific body of knowledge (i.e. the scholarly knowledge base) comes in the foreground. The change process (of situational inquiry) is instrumental in relation to these research purposes of creating abstracted knowledge. The situational inquiry establishes possibilities to test certain ideas and conjectures and to provide rich empirical data for theoretical analysis. There is a mutuality of purposes in action research (which is emphasized in MGAR). The change process and its empirics serve the research aims. Continual theorizing during an AR endeavor serves the performance of situational inquiry and the accomplishment of suitable organizational changes.

This principle of purpose mutuality can be understood in the following way (based on the MGAR process model; Fig. 2): The sub-process of theorizing serves situational inquiry with abstract knowledge that is practically useful ("knowledge \& tools/instrumental theory"). Certain demands for such knowledge can be stated from SI to theorizing ("knowledge \& tool needs"). The sub-process of situational inquiry serves theorizing with empirical data as a basis for theoretical development. Certain demands for empirical opportunities can be raised from theorizing to situational inquiry ("knowledge needs"). This MGAR principle is formulated in the same spirit as the other two MGAR principles. It follows the dialectics of theory and empirics in MGAR. The multi-grounding thinking is not to give one strict means-to-ends relation between situational knowledge development (empirics) and theory development. These spheres are mutually constitutive as in formulating purposes (principle 3 ) and as in knowledge development (principles 1 and 2).

\section{A multi-grounded action research case: effective IT service management}

\subsection{Case introduction}

The purpose of this section is to introduce the research project we have selected to illustrate how MGAR can be applied. The research project included a research interest oriented towards organizational change and a number of research interests related to theory generation. The research interest related to organizational change 
consisted of the development of digital tool supporting practitioners (service providers and customers) to collaboratively assessing IT services in the domain of ITSM. This interest provided several opportunities to identify theoretical research interests: (a) formulation of nascent theory in terms of generic service-oriented guidelines that support development of digital tools for assessment of IT services Göbel and Cronholm (2016), and (b) contribution to theory with regard to a model for selecting core processes Göbel et al. (2014), (c) a model including quality measurements developed from a customer perspective Cronholm and Salomonson (2014) and (d) evaluation of service perspectives in ITSM Göbel and Cronholm (2017).

The research project was previously published as a design-oriented action research project (Göbel and Cronholm 2016). However, the research project constitutes a suitable case that we have reinterpreted in order to illustrate MGAR. Overall, the research project was conducted in an MGAR spirit, although the term MGAR was not invented when the project was carried out. We can conclude that the case corresponds well to the purpose of applying MGAR since it enabled the development of organizational practices through the implementation of a digital tool. The tool was (1) shaped by the practitioners' organizational knowledge and (2) informed by selected extant theories. MGAR also includes support for theorizing about practices, which in this highly empirically case was a point of departure for making theoretical contributions. In the selected case, the digital tool created a number of opportunities to contribute to new knowledge. The theoretical contributions mentioned above relied heavily on access to empirical data and on extant theory. Consequently, the case consisted of excellent conditions for the illustration of empirical, internal and theoretical grounding with regard to the processes of situational inquiry and theorizing.

\subsection{Case description}

The purpose of this section is to describe the characteristics of the selected case in order to provide a background for the illustration of the MGAR processes and the MGAR principles. As mentioned above, the case was conducted in the domain of ITSM. Traditionally, the ITSM practice has been dominated by technical perspectives and a one-sided service provider perspective. Several scholars have reported on challenges in ITSM such as: a need for enhanced customer focus (e.g. Galup et al. 2009; Pollard et al. 2009), high costs (e.g. Eikebrokk and Iden 2017; Cronholm and Persson 2016) and lack of efficiency (Addy 2007; Galup et al. 2009). Based on the literature study, we can conclude that the customer ${ }^{1}$ perspective and the service-oriented perspective have not been sufficiently focused. This conclusion is supported by Cronholm and Göbel (2016) who state that there is a need to become a more process oriented and customer oriented for the management of IT as a service.

The research project was conducted in close collaboration with IT practitioners. It included seven organizations and four researchers (see Table 3). The research project lasted for 3 years. The participating organizations were facing challenges concerning

\footnotetext{
1 "Customer" is used in a broad sense including the customer organization as a whole and the actual users of the IT service.
} 
Table 3 Participating organizations

\begin{tabular}{lll}
\hline Type of business & Public/private & Size \\
\hline Forest, paper and logistics & Private & Medium \\
Logistics and transport & Private & Medium \\
Automotive dealership services & Private & Medium \\
IT-department, academy & Public & Medium \\
IT-consultant & Private & Large \\
Social service support tools & Private & Medium \\
IT-consultant & Private & Small \\
\hline
\end{tabular}

a lack of a service-oriented perspective. Even though the organizations had slightly different business objectives they all agreed to the need for and an interest in emphasizing a service-oriented perspective on their IT work in order to increase the focus on customer value. This challenge, which had both theoretical and empirical relevance, constituted the point of departure for the design-oriented action research project.

The role of the practitioners was to contribute (1) with organizational knowledge as a basis for the requirement specification for the design of the digital tool, (2) to the evaluation of the digital tool, and (3) with feedback from the organizational changes due to the implementation of the digital tool. The role of the researchers was primarily to facilitate the design-oriented action research project with a threefolded purpose:

- Continuous shift in focus between the specific characteristics of each individual organization and the collaborative cross-organizational arena with the aim of facilitating inter-organizational learning and generalization of results, both to the ITSM practice domain and to the scientific field.

- Development of a digital tool for assessment of IT services by intervening in the participating organizations' real contexts.

- Contributing to theory: formulation of generic guidelines that support the development of digital tools for assessment of IT services, development of a model for selecting core processes, development of a model including quality measurements from a customer perspective, and creating knowledge concerning the presence of a strong service perspective in ITSM.

In the research project, there was an interplay between the development of the theoretical contributions and the development of the digital tool. The theoretical contributions were not only informed by extant theory, but they were also highly influenced by empirical evidence collected from the development and evaluation of the digital tool. In parallel, the design of the digital tool was based on the emergence of the contributions to theory. Consequently, there was a mutual influence between the emergent theoretical contributions and the development of the digital tool.

In total, the case was conducted in three iterations. We conducted 30 interviews with IT managers and operational staff. To gain a shared understanding between the 
seven organizations, six workshops were conducted. In these workshops, the organizations learned from each other and not just from dyadic researcher-practitioner interventions. This additional learning meant that the organizations and the research project as a whole gained an enhanced generic and abstract understanding of the challenges related to service orientation.

\subsection{Empirical grounding of MGAR}

The purpose of this section is to illustrate MGAR by re-interpreting the case described in the previous sections. In the case, the two MGAR processes theorizing and situational inquiry have been conducted in parallel, but they are separately described below. A key idea of MGAR is that both the change outcome and the theory outcome should be multi-grounded. Consequently, this section includes descriptions of the outcome of the two processes in terms of the three MGAR principles: multi-grounded change outcome, multi-grounded theory outcome, and mutuality of processes. Below, we have illustrated all the constituent activities in the two processes of situational inquiry and theorizing, and how the multi-grounded action research knowledge model has guided us. We have also described the change outcome (=MGAR principle 1$)$ and the theory outcome (= MGAR principle 2). The third MGAR principle 'mutuality of purposes' is discussed and illustrated at the end of this section.

\subsubsection{Situational inquiry}

\section{Pre-evaluate}

Empirical grounding: In order to gain situational knowledge, we intervened in the empirical world of local practices. The researchers interviewed IT managers and IT consultants in order to diagnose the current state with respect to collaborative support for the assessment of IT services. These interviews were conducted individually in each organization. The purpose of the interviews was to collect information about challenges, problems, and goals. The result of the interviews was analyzed in order to present a diagnosis consisting of problem formulations, goals and initial requirements concerning a digital tool supporting collaborative assessment. Second, an initial workshop including all the organizations was organized. The purpose of the workshop was to gain a richer understanding of the problems and to agree about the problem formulations. The purpose of conducting both individual interviews and a workshop was to identify both specific and generic organizational challenges. The research question read: How could a structured support for collaborative service assessment and service innovation be designed?

Theoretical grounding: The selection of extant theories was guided by the diagnosis result. The purpose of using extant theories was to theoretically ground the diagnosis results by either confirm them or complement and enrich them 
by existing knowledge. The diagnosis result guided us in searching for extant theories. Below, we present a number of examples of extant theories that were consulted:

(a) Open innovation (e.g. Chesbrough 2003), which supported us to include knowledge concerning collaboration beyond organizational boundaries.

(b) Vargo and Lusch (e.g. 2004, 2008, 2016), which supported us to identify a contemporary service logic that included concepts such as value co-creation, resource integration and service-oriented perspectives supporting customer orientation.

(c) Customer-relationships (e.g. Grönroos 1994), which supported us to identify knowledge concerning marketing relationships and mutual exchange between the parties on the market.

(d) User experiences (e.g. Hassenzahl and Tractinsky 2006), which supported us to specify requirements for the digital tool from a user perspective (i.e. service provider and customer perspective).

(e) ITSM (e.g. Cater-Steel (2009), which supported us to design integrated core processes as an end-to-end service and Iden and Eikebrokk (2015), which supported as to focus on efficiency.

The multi-grounded change outcome from the pre-evaluate phase consisted of:

- Diagnosis result.

- Shared knowledge among the participating organizations about the current situation.

- Increased knowledge about the state of the art concerning service orientation and existing digital support.

- Initial problem formulation: lack of a digital tool supporting practitioners (service providers and customers) to collaboratively assessing IT services in the domain of ITSM.

- Knowledge informed by theories.

\section{Plan \& design}

The result of the considerations about how to collect information with respect to the design and evaluation of the digital tool was to intervene in the organizations' real environments. The actual coding of the tool was planned to be carried out by a programmer employed by the university. Due to the possibility to identify specific organizational interests, we decided to collect requirements individually in each organization. In order to identify generic requirements, we carried out a workshop including all the organizations. Another purpose of the workshop was to establish an arena for the organizations to learn from each other. We also planned close interaction with the process of theorizing since the emergent theories in this MGAR process in combination with extant theory guided each new version of the digital tool. This meant that a new version of the tool was used in each iteration. 
The multi-grounded change outcome from the plan $\&$ design phase consisted of:

- Plan for intervention (i.e. data collection and data analysis with respect to the design and evaluation of the digital tool).

- Plan for interaction with the process of theorizing.

- New version of the digital tool prepared for intervention.

\section{Test \& intervene}

Empirical grounding: The purpose of this activity was to analyze situational knowledge collected from the participating organizations in order to develop a proposal for change (a digital tool supporting service assessment). The digital tool was iteratively tested in 21 workshops organized in seven empirical settings. Each workshop was organized as follows: (1) The service providers and the customers jointly assessed an IT service supported by the digital tool. The assessment involved service providers and customers collaboratively assessing the IT service. The researchers acted as facilitators. (2) Joint discussions and reflections on how the tool supported the assessment process, and (3) the researchers conducted individual interviews of the involved service providers and customers. Each workshop included: 1-2 researchers, 1-2 service providers, and 1-2 customers.

The multi-grounded change outcome from the phase test $\&$ intervene included increased business knowledge with respect to:

1. The service providers' understanding of the customers' needs, and values.

2. The customers' insights into the service providers' cost drivers.

3. The customers' understanding of different service levels.

4. Identification of important measurements from a customer perspective.

5. Increased knowledge of core processes and inefficient processes.

6. Ideas for new and refined requirements with regard to the redesign of the digital tool.

\section{Post-evaluate}

Empirical grounding: The result from the interviews and the notes taken during the workshops were analyzed by the researchers. The result of the analysis increased the knowledge about the organizations' challenges, and it constituted a base for developing a refined requirements specification. The requirement specification was approved by the organizations before it was used to further improve the digital tool.

Theoretical grounding: The result of the analysis was compared to and influenced by extant and emerging theories. This meant that the tool development used emergent conceptualizations of IT service quality.

Internal grounding: Analysis of coherence of implemented concepts. Analysis of the relationships between activities in the core process, which were implemented in the tool. 
Multi-grounded change outcome: The main contribution to practice consisted of a digital tool that was jointly developed by service providers, customers, and researchers. The tool enabled improved dialogues between service providers and customers, which encouraged the two parties to especially focus on the quality of the services, the resources needed and the customer orientation.

The quality of the digital tool was based on:

- A shared understanding of each other's business (service provider, customer).

- Identification of core processes.

- Strengthened relationships between the service provider and the customer due to close collaboration.

- The insight that customer value cannot be delivered by service providers.

\subsubsection{Theorizing}

\section{Prepare}

The preparations included the following actions:

1. The identified challenges in process of 'Situational inquiry' constituted the base for identifying extant theories. As mentioned in Sect. 5.3.1, we identified a number of theories that supported our understanding of the challenges. However, we also identified a lack of knowledge regarding service-orientation in the IT sector.

2. Formulation of research questions/research interests: Development of knowledge concerning: generic service-oriented guidelines supporting the development of digital tools for assessment of IT services, core processes in ITSM, customeroriented quality measurements, and the service perspective in ITSM.

3. Establishment of the initial knowledge base for the study: Selection of extant theories from theories and perspectives concerning open innovation, service-dominant logic, customer-relationships, IT Service Management, and user experience (see examples above).

Multi-grounded theory outcome:

- Identified knowledge gaps concerning:

- Generic service-oriented guidelines concerning the assessment of IT services.

- A model for selecting core processes

- A model including quality measurements from a customer perspective

- Evaluation of service perspectives in ITSM

- Formulated research purposes and research questions.

- An established initial base of extant theory. 


\section{Continual theorizing}

Empirical grounding: (a) The formulation of the generic service-oriented guidelines for developing digital tools was based on the empirical evidence collected from tests of the digital tool in the process of situational inquiry. Abstractions and categorizations of the organizations' specific requirements were made in order to generalize the guidelines. (b) Collection of empirical evidence with respect to the identification of core processes for ITSM. 30 interviews including managers, developers, and process owners were conducted. (c) Development of a model including quality measurements from a customer perspective. 30 interviews including managers, developers, and process owners were conducted. (d) Evaluation of service perspectives in ITSM was conducted by organizing three workshops. The purpose of the workshops was to find ways of how to increase the knowledge about the service perspective in the IT sector. One idea was to use ITIL $^{2}$ as a tool to distribute contemporary serviceoriented knowledge. Consequently, the workshop included to discuss how the service perspective was included in the core processes of ITIL. In order to ensure broad approach, the workshop included both practitioners and researchers. The researchers contributed with knowledge concerning service-dominant logic, while the practitioners contributed with experiences from use of ITIL in IT related projects. Conceptualizations, use of language and perspectives were discussed and compared.

Theoretical grounding: To formulate theorized knowledge, we relied on the empirical grounding described above and on extant theories. Insights gained from extant theories were used to compare the knowledge generated from the empirical grounding (the emergent theory). One example of a generic guideline reads:

If you want to design an IT artefact for the purpose of enabling service innovation and service assessment in the context of ITSM, then you are best advised to give that intervention the characteristic of value co-creation, and to do that via the procedure design dynamic change processes uniting all actors in the service ecosystem, because of the argument that access to shared resources will leverage the innovation process.

The guideline includes several elements that are derived from theory. One specific element is value co-creation, which is derived from service-dominant logic (e.g. Vargo and Lusch 2004). Another element is shared resources, which can be traced to theories about open innovation (e.g. Chesbrough 2003). The result of the comparisons both confirmed and provided new insights. In this way, the extant theories played an important role to enhance and guide the research interests.

Internal grounding: Included an analysis of coherence of the 'final' knowledge concerning the generic service-oriented guidelines supporting the development of digital tools for assessment of IT services, the core processes in ITSM, the customer-oriented quality measurements, and the service perspective in ITSM.

Multi-grounded theory outcome:

${ }^{2}$ ITIL is a world-wide de facto standard/framework in the ITSM practice (e.g. Karu et al. 2016). 
- Emerging knowledge concerning: generic service-oriented guidelines supporting the development of digital tools for assessment of IT services, core processes in ITSM, customer-oriented quality measurements, and the service perspective in ITSM.

- A research paper was jointly written by practitioners and researchers (Cronholm et al. 2017).

\section{Conclude}

The creation of the 'final' theory comprised an overall analysis of the empirical grounding, theoretical grounding and internal grounding conducted in all the activities of the process of theorizing. It also included analyzing the interaction with the process of situational inquiry (especially the theories' relationship to the digital tool).

Multi-grounded theory outcome: The contribution to theory includes knowledge concerning: generic service-oriented guidelines supporting the development of digital tools for assessment of IT services, the core processes in ITSM, the customeroriented quality measurements, and the service perspective in ITSM.

Some comments need to be made concerning these illustrations. Sometimes the change and theory outcome can partially coincide when being a knowledge result, but there are important differences. The change outcome is always situational, i.e. adapted and applied in some specific local practice. The theory outcome should be abstracted aiming for generalized knowledge leaving out situational characteristics. Even if the change outcome comprises some knowledge result, there are always broader outcomes as changes in ways of working, situational understanding and new/changed artifacts.

The empirical groundings of the different outcomes may often coincide to a large degree, but there may also be important differences. If the theory outcome is more concerned with the change process rather than change outcome, this will probably imply needs for other types of empirical data than is naturally created through the change process. For example, opinions from participants on how they have experienced the change process may be needed.

Theoretical grounding of change outcome is directly based on the theorizing process (such as emergent conceptualization) during the AR endeavor; and through this, it indirectly relies on extant theory. The theoretical grounding of the theory outcome has a direct orientation to extant theory working explicitly with matching new theoretical contributions with the existing body of knowledge.

As previously described, MGAR aims at both organizational change and scientific knowledge contribution. This aim is supported by an extensive exchange of knowledge and information between the processes of situational inquiry and theorizing. The interplay between these two sub-processes is illustrated in the case illustration above. One example can be found in the activity "Plan \& Design", which included the implementation of guidelines developed in the parallel process of theorizing. That is, the conduct has implied a continual interplay between theorizing and situational inquiry. The theorizing (as investigating theoretical sources and continual reflection and conceptualization) has supported the change processes. Empirical 
data from the situational inquiries has served the theorizing processes. This knowledge interplay between theorizing and situational inquiry follows the MGAR principle of mutuality of purposes.

\section{Discussion and conclusions}

\subsection{Improvement of IT service management through multi-organizational cooperation and action research}

The delivery of IT services still struggles with too much techno-centrism and too little focus on customer values. The advent of IT service management is a response to the need to get IT more aligned with core businesses of organizations. Albeit the introduction of ITSM approaches (such as ITIL), there are still unsettled problems to address. Marketed ITSM approaches are claimed to be "best practices", but the implementation and application of such approaches do not, far from always, establish ways of working that are satisfactory for customers and service-providers. This paper has demonstrated one way to address this demanding challenge: the accomplishment of action research in a multi-organizational ITSM setting. To work with several organizations have been important in order to establish a broad problem understanding that is not restricted to specific situational circumstances. The multiorganizational setting provided also a varied test arena to try out new ideas. Action research has been a way to not only identify and characterize ITSM problems but also to find new ways to address these issues and attempting to improve ways of working. An emergent focus in these studies has been on the assessment of IT service quality. Without a multi-organizational $A R$, it might have been hard to reach the insight of how significant it is to obtain improved ways of communicating among service-providers and customers. Important contributions (both in practice and scholarly formulated) were reached concerning the assessment of IT service quality (such as IT service quality guidelines, an IT tool, quality measures).

\subsection{MGAR as a response to posed research question and stated issues and concerns}

We formulated the following research question as guiding for this paper: How can knowledge development in action research be clarified and improved through the use of multi-grounding principles? The articulation of MGAR is thus a response to this research question. There are two aspects in the research question that need to be addressed, i.e. the aims for clarification and improvement. The clarification aim is reached mainly through how we have conceptualized AR in our three MGAR models and how we describe and label different activities and (knowledge) objects. The aim is thus also to present a research approach that can improve action research in IS. We will discuss this further below in this and next sections.

Based on a literature review, the formulated research question was detailed in six stated issues and concerns (Table 1). The multi-grounded action research can be 
Table 4 Summary of MGAR as a response to unsettled issues and concerns (from Table 1)

Issues and concerns in IS action research

\#1. How should problem-solving and theorizing interact during AR?

\#2. How should theory be used in AR?

\#3. How should theory be generated in AR?

\#4. How can research purposes and problemsolving purposes interact in AR?

\#5. What are the roles of data collection and data analysis for problem-solving and theorizing in AR?

\#6. What is the role of design in AR?
MGAR essential characteristics

Problem-solving (situational inquiry) and theorizing are activities that run in parallel during AR. There is a continual flow of knowledge between these activities. Theorizing is serving situational inquiry with instrumental theory. Situational inquiry is serving theorizing with empirical data (concerning the problematic situation in current practice, proposals for change and effects from changed practice)

Extant theory can be used to inform theorizing in an abductive way. Theory should be used to inform the different phases of situational inquiry; however initial primacy should be given to situational conditions. Such a useful theory is called instrumental theory and can be extant and/or emergent theory

Theorizing is a continual process during AR; aiming for both support (as instrumental theory) to situational inquiry/change and the creation of final theory outcome with research community as the main target

The generation of emergent theory can be conducted initially through an inductive approach studying empirical data that are generated in an openminded way. Further theorizing can preferably be performed in an abductive way bringing in extant theory. This means that such a theory should be empirically, theoretically and internally grounded

Practitioners are engaged in AR to obtain support for resolution of organizational problems and to get access to scholarly knowledge. Researchers engage in such an organizational problem-solving process in order to address practically relevant research needs and thereby contribute to practical development

The role of problem-solving, as a change-oriented empirical inquiry within AR, is thus clarified. The role of theorizing, as a knowledge supportive activity to problem-solving, is also clarified

Research purpose is distinct from problem-solving purpose, but these purposes must be mutually supportive

Inquiry activities (such as data collection and evaluation) are integral in the organizational change process. Additional data collection can be performed based on specific research purposes (e.g. testing of conjectures and special needs for theory development)

Design has a prominent role in situational inquiry; phase 2 "plan \& design". Results from design need to be used, tested and evaluated (in phases 3 and 4). MGAR is harmonious with research approaches of design science within IS 
seen as a response to these unsettled issues and concerns in IS action research. In Table 4, we describe, in a condensed way, MGAR as a response to these issues and concerns. This table can be seen as a summary of MGAR (concepts, processes, and principles).

The development of MGAR has been based on such multi-grounding principles itself. The creation of MGAR is founded on (1) own experiences from action research and similar approaches, (2) close studies of literature on action research and epistemologies of qualitative research and (3) a strong ambition to create a coherent and harmonious whole.

\subsection{MGAR in relation to extant AR knowledge}

We do not believe in one superior action research approach to be used in all possible AR cases (see discussion above in Sect. 1.2). An applied AR approach needs to be contingent to both situational and research circumstances. There is room in the scholarly knowledge base for different AR approaches.

MGAR is aimed to be one such AR approach intended for scholars who find its traits as useful in a practical research situation. We claim that MGAR covers important aspects of an AR endeavor, and as such, it may be used as a main research approach. However, different aspects of MGAR might be possible to use in combination with other research approaches; this can be AR approaches or other kinds of research approaches. We recall now parts of our literature review from above (Sects. 1.1 and 2) and position what has been achieved in this paper (MGAR models and principles) in relation to that extant AR knowledge. This will not be a thorough review and comparison due to limited space. The aim with this brief review is to help scholars further in navigation in the IS AR landscape, of course, here with MGAR as the focal point. We will below discuss affinities, similarities, and differences between MGAR and several other AR approaches.

The dual cycle differentiation of AR is an important conceptualization (McKay and Marshall 2001). MGAR builds on a similar differentiation although other labels have been chosen. MGAR gives clearer advice concerning the interaction between these cycles. Actually, McKay and Marshall 2001) do not say much about epistemological strategies. However, Chiasson et al. (2008) and Mathiassen et al. (2012) build on the dual cycle differentiation and have complemented with an analysis of epistemological strategies (deductive, inductive, interactive). MGAR embrace an inductive approach initially conducted, followed by an abductive approach that comes close to "interactive" as Chiasson et al. (2008) call it.

Davison et al. (2004, 2012) have elaborated Canonical Action Research (CAR) as an important approach in IS. One of the principles in CAR is the principle of researcher-client agreement, which states the formal arrangement between these primary AR stakeholders. This is of outmost importance for AR success and we adhere fully to this principle. In MGAR nothing more is said about this and we recommend to follow this principle. There exist, however, several important differences between CAR and MGAR. CAR uses a sequential and cyclical model of the $\mathrm{AR}$ with a primary focus on the problem-solving process. As has been described 
above (Sect. 4.1), there exist similarities between these problem-solving phases, although there are motivated differences in terminology. CAR adopts a cyclical onelayer process and MGAR adopts a dual two-layered process giving equal emphasis to theorizing and problem-solving (situational inquiry). CAR emphasizes a deductive approach with the use of instrumental theory as supportive to different problem-solving phases. MGAR acknowledges also a use of instrumental theory in all problem-solving phases, but it emphasizes also the need for a situation-sensitive and inductive inquiry. MGAR has also elaborated how an abductive and multi-grounded approach should be applied for the generation of both situational and theoretical knowledge.

Grounded Action Research (GAR) by Baskerville and Pries-Heje (1999) adds classical inductive GT to AR. GAR emphasizes data collection and open coding during different AR phases. GAR shares such an inductive approach with MGAR. However, MGAR is a more compound approach that also includes abductive and multi-grounded knowledge development. In GAR there is no place for any use of theory for the development of theory or for problem-solving. Such a theory use is a key feature in MGAR.

There exist several AR approaches that have been fused with elements from design science research. Action Design research (ADR) by Sein et al. (2011) is one prominent approach to design-oriented action research. There are similarities between ADR and MGAR concerning dual and alternating processes. Reflection and abstraction are running in parallel with problem-solving and design in ADR. This is similar to the type of dual processes in MGAR (theorizing and situational inquiry). The problem-solving process is, however, conceptualized in different ways in the two AR approaches. In ADR there is an interleaving of "building, intervention, and evaluation". These activities (and others) are analytically differentiated in clear ways in MGAR. ADR proposes an active use of theory to inform problem analysis and design, which is similar to MGAR. However, in ADR, it seems to be an emphasis on deductive theory-driven analysis and design, as opposed to an open and inductive inquiry that is also embraced in MGAR. The situational problem-solving (in ADR) is supported by an abstract process of problem-solving working with "classes of problems" and "classes of solutions". Such an approach of supportive abstract problem-solving is even more evident in soft design science methodology (SDSM) by Baskerville et al. (2009). In SDSM there is a foundational differentiation between situational and general abstract layers, which is similar to MGAR even if other terms are used. In SDSM, the problem-solving should be performed through abstraction and clarifying general problems and solutions and then, these general solutions should be applied to the specific problematic situation. There is a great reliance on abstraction as a means for problem-solving. Even if abstraction is honored in MGAR, this is not the way problem-solving and design is described. There is instead an emphasis on a situational inquiry in order to find suitable solutions. This situational process is guided by instrumental theory (of emergent and extant types). Grounded design (GD) by Rohde et al. (2016) takes an even firmer position against an abstract process of problem-solving and design. Based on ethnographic ideals, GD advocates a tight closeness to the practice setting in design and a continual appropriation of solutions before a settlement can be said to be reached. In GD, there seems to be skepticism against the use of theory in the design process and a preference 
for situational creativity in design. MGAR welcome the use of instrumental theory if it is applied in an unobtrusive way in the situational inquiry.

Technical action research (TAR) by Wieringa and Morali (2012) works also with a differentiation of abstract versus concrete problems and solutions. However, TAR takes a special position concerning design and problem-solving. It starts with a design of an artifact dependent on general problem views. TAR then finds an organizational case to test and apply this artifact. This kind of "solution finds a problem" is far from MGAR and other design-oriented AR approaches, such as ADR, SDSM, and GD. All these other AR approaches works with a problem and situationally driven design.

Taken the actual case (ITSM), one question to ask is if similar results could have been reached with some other approach. There are many contingencies concerning achieved results in AR studies, which imply that it is hard to give a definitive answer. A general answer could be that the MGAR approach implies a greater probability to reach multi-grounded theory and change outcomes since these values are explicitly accounted for. These values might be reached through other research approaches (without such explicit concerns), but in such cases, it is more by chance than by deliberation and intention.

\subsection{Concluding remarks and future research}

We propose multi-grounded action research as a way to revitalize AR in IS research. MGAR incorporates several important traits such as:

- An integral and well-thought design orientation

- Empirically grounded knowledge development enhanced with broader epistemological principles of theoretical and internal grounding

- A dynamic and mutually supportive interplay between an inquiry/change process and a continual theorizing

Produced scholarly knowledge should be deliberate responses to un-resolved concerns and challenges. At the same time, such knowledge contributions are always provisional and in a state of becoming. This counts of course for the MGAR approach, which should not be seen as a finalized product. Several needs for further research can be seen:

- Further theoretical grounding of MGAR in relation to qualitative research epistemologies and intervention theory

- More thorough comparisons between MGAR and other similar research approaches

- Further clarification of the interaction between theorizing and situational inquiry

- Further clarification of the relations between intervention and design

- More concrete "hands-on" advice for the application of MGAR in practice

- Further application of MGAR in real AR cases with more detailed empirical analysis and validation of this applied research approach 
We will pursue research in these directions and invite other scholars to partake in such endeavors.

Acknowledgements Open access funding provided by Linköping University. We gratefully acknowledge the financial support of the Knowledge Foundation, without which the present study could not have been completed. We are also grateful to the participating organizations that have collaborated in the AR project.

Funding Funding was provided by the Knowledge Foundation (Stiftelsen för Kunskaps- och Kompetensutveckling).

\section{Compliance with ethical standards}

Conflict of interest The authors declare that they have no conflict of interest.

Open Access This article is licensed under a Creative Commons Attribution 4.0 International License, which permits use, sharing, adaptation, distribution and reproduction in any medium or format, as long as you give appropriate credit to the original author(s) and the source, provide a link to the Creative Commons licence, and indicate if changes were made. The images or other third party material in this article are included in the article's Creative Commons licence, unless indicated otherwise in a credit line to the material. If material is not included in the article's Creative Commons licence and your intended use is not permitted by statutory regulation or exceeds the permitted use, you will need to obtain permission directly from the copyright holder. To view a copy of this licence, visit http://creativecommons.org/licen ses/by/4.0/.

\section{References}

Addy R (2007) Effective IT service management-from ITIL and beyond. Springer, Berlin

Argyris C, Putnam R, McLain Smith D (1985) Action science. Concepts, methods and skills for research and intervention. Jossey Bass, San Francisco

Avgerou C (2001) The significance of context in information systems and organizational change. Inf Syst J 11:43-63

Avison D, Wood-Harper T (1991) Information systems development research: an exploration of ideas in practice. Comput J 34(2):98-112

Avison D, Baskerville R, Myers M (2001) Controlling action research projects. Inf Technol People 14(1):28-45

Avison D, Davison R, Malaurent J (2018) Information systems action research: debunking myths and overcoming barriers. Inf Manag 55:177-187

Baskerville R (1997) Distinguishing action research from participative case studies. J Syst Inf Technol 1(1):24-43

Baskerville R (1999) Investigating information systems with action research. Commun AIS 2:19

Baskerville R, Myers M (2004) Special issue on action research in information systems: making IS research relevant to practice-foreword. MIS Q 28(3):329-335

Baskerville R, Pries-Heje J (1999) Grounded action research: a method for understanding IT in practice. Account Manag Inf Technol 9:1-23

Baskerville R, Wood-Harper T (1998) Diversity in information systems action research methods. Eur J Inf Syst 7:90-107

Baskerville R, Pries-Heje J, Venable J (2009) Soft design science methodology. In: Proceedings of DESRIST'09, Malvern

Boland RJ, Collopy F (eds) (2004) Managing as designing. Stanford University Press, Stanford

Bryant A, Charmaz K (2007) Introduction. Grounded theory research: methods and practices. In: Bryant A, Charmaz K (eds) The SAGE handbook of grounded theory. SAGE, London 
Cater-Steel A (2009) IT service departments struggle to adopt a service-oriented philosophy. Int J Inf Syst Serv Sector 1(2):69-77

Checkland P (1991) From framework through experience to learning: the essential nature of action research. In: Nissen H-E, Klein H, Hirschheim R (eds) Information systems research: contemporary approaches and emergent traditions. North-Holland, Amsterdam

Checkland P (2000) Soft systems methodology: a thirty year retrospective. Syst Res Behav Sci 17:11-58

Chesbrough $\mathrm{H}$ (2003) The logic of open innovation: managing intellectual property. Calif Manag Rev 45(3):33-58

Chiasson M, Germonprez M, Mathiassen L (2008) Pluralist action research: a review of the information systems literature. Inf Syst J 19(1):31-54

Corbin J, Strauss A (2008) Basics of qualitative research. Techniques and procedures for developing grounded theory, 3rd edn. Sage, Thousands Oaks

Craig RT, Tracy K (1995) Grounded practical theory: the case of intellectual discussion. Commun Theory 5(3):248-272

Cronen V (2001) Practical theory, practical art, and the pragmatic-systemic account of inquiry. Commun Theory 11(1):14-35

Cronholm S, Göbel H (2016) ITIL compliance with a service perspective: a review based on servicedominant logic. In: The 27th Australasian conference on information systems, Wollongong

Cronholm S, Persson L (2016) Best practice in IT service management: experienced strengths and weaknesses of using ITIL. In: Proceedings of the international conference on management, leadership and governance, St. Petersburg

Cronholm S, Salomonson N (2014) Measures that matter: service quality in IT service management. Int J Qual Serv Sci 6(1):60-76

Cronholm S, Kaimar K, Göbel H, Hearsum P, Hero P (2017) IT service management: the alignment of ITIL practitioner with service-dominant logic. In: Proceedings of 28th Australasian conference on information systems (ACIS), Hobart

Davison RM, Martinsons MG, Kock N (2004) Principles of canonical action research. Inf Syst J 14:65-86

Davison RM, Martinsons MG, Ou C (2012) The roles of theory in canonical action research. MIS Q 36(3):763-786

Dewey J (1938) Logic: the theory of inquiry. Henry Holt, New York

Dick B (2007) What can grounded theorists and action researchers learn from each other? In: Bryant A, Charmaz K (eds) The SAGE handbook of grounded theory. Sage, London

Eden C, Huxham C (1996) Action research for management research. Br J Manag 7:75-86

Eikebrokk T, Iden J (2017) Strategizing IT service management through ITIL implementation: model and empirical test. Total Qual Manag Bus Excell 28(3-4):238-265

Galup S, Dattero R, Quan J, Conger S (2009) An overview of IT service management. Commun ACM 52(5):124-127

Glaser B (1992) Basics of grounded theory analysis: emergence vs. forcing. Sociology Press, Mill Valley

Glaser B, Strauss A (1967) The discovery of grounded theory. Aldine, New York

Göbel H, Cronholm S (2016) Nascent design principles enabling digital service platforms. In: DESRIST-2016 proceedings, New Foundland

Göbel H, Cronholm S (2017) Guidelines for service-dominant logic: empirical experiences from IT service management. In: Proceedings of the 4th Naples forum on service, Naples

Göbel H, Cronholm S, Hallqvist C, Söderström E, Andersson L (2014) IT service management: core processes aligning business and IT. In: Business information systems workshops. Springer, pp 145-155

Goldkuhl G (2004) Design theories in information systems-a need for multi-grounding. J Inf Technol Theory Appl (JITTA) 6(2):59-72

Goldkuhl G (2012) From action research to practice research. Austral J Inf Syst 17(2):57-78

Goldkuhl G, Cronholm S (2010) Adding theoretical grounding to grounded theory-towards multigrounded theory. Int J Qual Methods 9(2):187-205

Goldkuhl G, Cronholm S (2018) Multi-grounded theory—an update. Int J Qual Methods 17:1-5

Goldkuhl G, Lind M (2010) A multi-grounded design research process. In: DESRIST-2010 proceedings, LNCS 6105. Springer, Berlin

Goldkuhl G, Sjöström J (2018) Design science in the field: practice design research. In: DESRIST-2018 proceedings, LNCS 10844. Springer, Berlin, pp 67-81

Gregor S (2006) The nature of theory in information systems. MIS Q 30(3):611-642

Grönroos C (1994) From marketing mix to relationship marketing. Towards a paradigm shift in marketing. Manag Decis 32(2):4-32 
Habermas J (1984) The theory of communicative action 1. Reason and the rationalization of society. Polity Press, Cambridge

Hassenzahl M, Tractinsky N (2006) User experience—a research agenda. Behav Inf Technol 25(2):91-97

Heron J, Reason P (2001) The practice of co-operative inquiry: research 'with' rather than 'on' people. In: Reason P, Bradbury H (eds) Handbook of action research. Sage, London

Hult M, Lennung S-Å (1980) Towards a definition of action research: a note and bibliography. J Manag Stud 17:241-250

Hultgren G, Goldkuhl G (2013) How to research e-services as social interaction: multi-grounding practice research aiming for practical theory. Syst Signs Actions 7(2):104-120

Huxham C (2003) Action research as a methodology for theory development. Policy \& Politics 31(2):239-248

Iden J, Eikebrokk T (2015) The impact of senior management involvement, organisational commitment and group efficacy on ITIL implementation benefits. IseB 13(3):527-552

Iivari J (2015) Distinguishing and contrasting two strategies for design science research. Eur J Inf Syst 24:107-115

Karlsson F, Ågerfalk P (2007) Multi-grounded action research in method engineering: the MMC Case. In: Ralyté J, Brinkkemper S, Brian Henderson-Sellers B (eds) Situational method engineering: fundamentals and experiences. Springer, Berlin

Karu K, Ferris K, Hunnebeck L, Rae B, Rance S (2016) ITIL practitioner. The Stationery Office

Kelle U (2005) "Emergence" vs "forcing" of empirical data? A crucial problem of "grounded theory" reconsidered. Forum Qual Soc Res 6(2):133-156

Kling R, Lamb R (1999) IT and organizational change in digital economies: a socio-technical approach. Comput Soc 29(3):17-25

Kock N (ed) (2007) Information systems action research. An applied view of emerging concepts and methods. Springer, Berlin

Kock N, Lau F (2001) Information systems action research: serving two demanding masters. Inf Technol People 14(1):6-11

Kuechler B, Vaishnavi V (2012) A framework for theory development in design science research: multiple perspectives. J AIS 13(6):395-423

Lau F (1997) A review on the use of action research in information systems studies. In: Liebenau J, DeGross J (eds) Lee A. Information systems and qualitative research. Chapman \& Hall, London

Lee JS, Pries-Heje J, Baskerville R (2011) Theorizing in design science research. In: DESRIST 2011, LNCS 6629. Springer, Berlin, pp 1-16

Lewin K (1947) Frontiers in group dynamics II. Channels of group life; social planning and action research. Hum Relat 1(2):143-153

Lindgren R, Henfridsson O, Schultze U (2004) Design principles for competence management systems: a synthesis of an action research study. MIS Q 28(3):435-472

Mårtensson P, Lee A (2004) Dialogical action research at Omega corporation. MIS Q 28(3):507-536

Mathiassen L, Chiasson M, Germonprez M (2012) Style composition in action research publication. MIS Q 36(2):347-363

McKay J, Marshall P (2001) The dual imperatives of action research. Inf Technol People 14(1):45-59

McKay J, Marshall P, Hirschheim R (2012) The design construct in information systems design science. J Inf Technol 27:125-139

Mumford E (2006) The story of socio-technical design: reflections on its successes, failures and potential. Inf Syst J 16:317-342

Pollard C, Gupta D, Satzinger J (2009) Integrating SDLC and ITSM to 'servitize' systems development. In: AMCIS-2009 proceedings

Rapoport R (1970) Three dilemmas in action research. Hum Relat 23(6):499-513

Rohde M, Brödner P, Stevens G, Betz M, Wulf V (2016) Grounded design-a praxeological IS research perspective. J Inf Technol 32:163-179

Schein E (2001) Clinical inquiry/research. In: Reason P, Bradbury H (eds) Handbook of action research. Sage, London

Sein M, Henfridsson O, Purao S, Rossi M, Lindgren R (2011) Action design research. MIS Q 35(1):37-56

Strauss A, Corbin J (1990) Basics of qualitative research. Grounded theory, procedures and techniques. Sage, Newbury Park

Susman GI, Evered RD (1978) An assessment of the scientific merits of action research. Adm Sci Q 23(4):582-603

Thornberg R (2012) Informed grounded theory. Scand J Educ Res 56(3):243-259 
Trist E (1981) The evolution of socio-technical systems. Occasional Paper No. 2, Quality of Working Life Centre, Toronto

van Aken J (2005) Management research as a design science: articulating the research products of mode 2 knowledge production in management. Br J Manag 16:19-36

van Maanen J, Sørensen J, Mitchell T (2007) The interplay between theory and method. Acad Manag Rev 32(4):1145-1154

Vargo S, Lusch R (2004) Evolving to a new dominant logic for marketing. J Mark 68(1):1-17

Vargo S, Lusch R (2008) Service-dominant logic: continuing the evolution. J Acad Mark Sci 36(1):1-10

Vargo S, Lusch R (2016) Institutions and axioms: an extension and update of service-dominant logic. J Acad Mark Sci 44(1):5-23

Wieringa R, Morali A (2012) Technical action research as a validation method in information systems design science. In: Proceedings DESRIST 2012, LNCS 7286. Springer, Berlin

Wittgenstein L (1958) Philosophical investigations. Basil Blackwell, London

Wulf V, Rohde M (1995) Towards an integrated organization and technology development. In: Proceedings of the symposium on designing interactive systems. ACM

Publisher's Note Springer Nature remains neutral with regard to jurisdictional claims in published maps and institutional affiliations. 